Submission ID: 43875

\title{
Geological Structure and Petroleum Potential of the Area High-Latitude $\mathrm{Ob}$
} Riverside

I. Panteleyko* (LUKOIL-Engineering Limited KogalymNIPIneft Branch in Tyumen), A. Rube (LUKOILEngineering Limited KogalymNIPIneft Branch in Tyumen), I. Supolkina (LUKOIL-Engineering Limited KogalymNIPIneft Branch in Tyumen), E. Gachegov (LUKOIL-Engineering Limited KogalymNIPIneft Branch in Tyumen)

\section{SUMMARY}

The present article is based on results of integrated geological-geophysical researches. The article illustrates short data of geological-geophysical surveys, geological structure and petroleum potential of the field, estimation of the region petroleum potential and recommendation for search drilling. 
Геологическое строение и перспективы нефтегазоносности в пределах Широтного Приобья

И.А. Пантелейко*, А.А. Рубе, И.В. Суполкина, Е.В. Гачегов (Филиал ООО "ЛУКОЙЛИнжиниринг" "КогалымНИПИнефть" в г. Тюмени)

\section{Введение}

В условиях истощения запасов нефти изучение глубоко залегающих отложений доюрского комплекса (далее ДЮК) в качестве перспективного объекта для восполнения минеральносырьевой базы является сегодня стратегически значимой задачей.

По оценкам экспертов, общее количество поисково-разведочных скважин, вскрывших доюрские отложения на территории ХМАО - Югры, составляет более 2950, но они располагаются по площади округа неравномерно. Достаточно хорошо изучена бурением западная часть округа (Шаимский и Турсунский мегавалы, Красноленинский свод). На востоке, где резко увеличена мощность отложений осадочного чехла, фундамент менее изучен, особенно на крайнем востоке округа.

В центральной части Широтного Приобья на территории деятельности ООО «ЛУКОЙЛЗападная Сибирь» общее количество поисково-разведочных скважин, вскрывших ДЮК, составляет 46. Большинство скважин вскрыло кровельную часть доюрских отложений (зону контакта) на глубину до 100 м - 19 скважин, от 100 до 300 м - 14 скважин, от 300 до 500 м семь скважин, от 500 до 1000 м - шесть скважин. Общий метраж вскрытых пород доюрского комплекса составляет 10042 м (в т.ч. 607 м проходка по корам выветривания). Величина изученности бурением доюрских отложений составляет 615 км²/скв.

Причина недоизученности доюрского разреза связана с отсутствием прогнозных критериев поиска УВ фундамента, отсутствием методик выделения коллекторов в кристаллических породах методами ГИС, способов их вскрытия и освоения.

\section{Методы исследования и фактический материал}

Проведен детальный визуальный анализ всех временных разрезов на площади в 28292 км² $^{2}$ с учетом этого анализа выполнена детальная корреляция разрезов глубоких скважин по данным ГИС. На основе комплексного анализа геолого-геофизического материала и интерпретации результатов всех сейсморазведочных работ и данных бурения построены и проанализированы детальные региональные структурные карты по кровле и подошве юрского комплекса (ОГ А и ОГ Б) и карта общих толщин юрского комплекса масштабе 1: 250000 (рисунок 1). Изучены государственная гравиметрическая карта в редукции Буге масштаба 1:200 000 и государственная магнитометрическая карта масштаба 1:50 000. Проанализированы описания керна и выполнен седиментологический анализ более 40 глубоких скважин.

\section{Геологическое строение}

Современную геоморфологию размытой поверхности ДЮК отражает поверхность сейсмоотражающего горизонта «А». По ОГ «А» выделяется ряд крупных антиклинальных структур - Тевлинско-Кочевской и Когалымский валы, Ватьеганское, Покачевское, Урьевское, Локосовское и др. поднятия, депоцентры Ярсомовского и Пякупурского прогибов и другие крупные структуры. Детально изучив структурный план по ОГ «А», отмечаем, что наиболее высокое залегание кровли доюрского комплекса (от -2789 до -2830 м) установлено на СевероПоточном и Урьевском месторождениях, в то время как абсолютные отметки максимально погруженного участка поверхности составляют -3810 м в пределах Северо-Выинтойского-2 ЛУ. Таким образом, осадконакопление в раннеюрское время протекало в условиях сложно расчлененного рельефа с перепадом высот на исследуемой территории более 1 км. На всех 
временных сейсмических разрезах в пределах ДЮК прослеживается большое количество дизъюнктивных дислокаций.

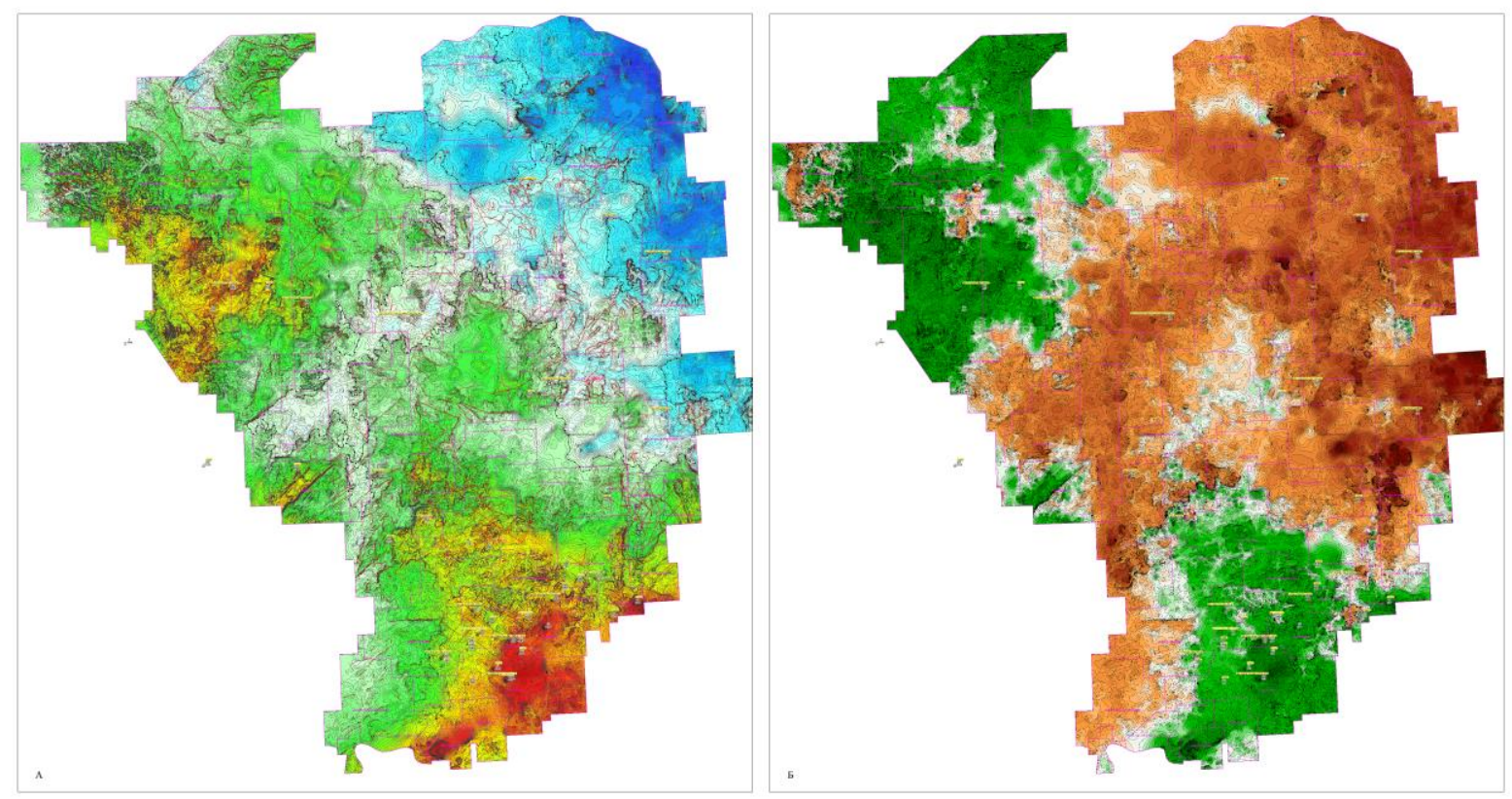

Рисунок 1 Структурная схема по кровле доюрского комплекса (А). Схема общих толщин юрских отложений (Б)

\section{Вещественный состав}

Освещенность керном доюрского разреза невысокая. Мощность изученных бурением доюрских пород составляет от 30 м (скв. 95Р Малоключевая) до 712 м (скв. 151 Лас-Еганская). В результате проведенного исследования по изучению и обобщению материалов полевого, лабораторного описания керна и шлифов, фотографий керна и шлифов, петрофизических свойств горных пород представляется возможным выделить следующие вещественные комплексы пород:

1. Группа терригенных пород коры выветривания, представленных песчаниками крупно- и грубозернистыми, аргиллитами черными углефицированными, брекчиями, глинистыми сланцами. Керн представлен переслаиванием песчаников коричневато-темно-бурых, тонкозернистых с глинистым цементом, с обломками каменного угля черного, с зеркалами скольжения на контакте с ДЮК (Д19 - 1190 Ватьеганская), песчаник с запахом нефти.

2. Группа пород основного состава, представленная умеренно щелочными эффузивами, андезито-базальтами, андезито-базальтовыми порфирами, базальтовыми порфиритами, базальтами, гиалобазальтами, диабазами и спилитами. Керн представлен базальтами, измененными серовато-светло-зеленой окраски, с многочисленными трещинками, выполненными хлоритом, альбитом и кварцем (230П Дружная, 152Р Лас-Еганская).

3. Группа пород кислого и среднекислого состава представлена эффузивами среднекислого состава, гранитами, гранодиоритами, гранит-порфирами, риолитами, туфами и трахириодацитами. В скважине 195П Нонг-Еганской керн представлен гидротермально измененными риолитами зеленовато-серыми, плотными. В скважине $21 П$ Урьевской гранитами крупнокристаллическими и пегматоидными со слабой хлоритизацией.

4. Группа карбонатных пород. Керн представлен доломитами хлоритизированными (Д12-14 $102 П$ Поточная), известняками доломитизированными, косослоистыми (Д20-25 - 2070П Поточная). Карбонатные породы трещиноватые, трещины выполнены кальцитом. 
5. Группа пород, представленная сланцами кристаллическими и парасланцами. Керн представлен аспидными сланцами черными с секущими жилками кварца и включениями полевых шпатов (Д18 - 131Р Северо-Поточная).

Группа пород среднего состава, обычно представленная габбро-диоритами и диоритами, на исследуемой территории не вскрыта. Установлено, что магматические и метаморфические породы кислого и основного состава, наиболее распространены в породах ДЮК. При сопоставлении информации о вещественном составе пород с геологическим строением и тектоническим развитием определено, что на исследуемой территории имело место развитие гранитных интрузий, приуроченных $к$ активным тектоническим зонам $\mathrm{c}$ крупными глубинными разломами, которые формировались на сравнительно небольшой глубине и совместно с кислыми эффузивами образовывали массив, сложенный магматическими породами кислого состава. На большей части месторождений геологический разрез ДЮК пород характеризуется вулканогенными породами основного состава, прорванного местами интрузиями кислого и средне-кислого состава.

Коллекторы ДЮК относятся к кавернозно-порово-трещинному типу. Первоочередными объектами поиска рассматриваются гранитоиды и коры выветривания, к которым приурочено более $80 \%$ разведанных запасов нефти и газа открытых месторождений в фундаменте (С.М. Беккина, И.Ш. Усманов), а также туффиты и эффузивы, подвергшиеся вторичным процессам выветривания и гидротермального изменения.

\section{Перспективы нефтегазоносности}

В пределах Нижневартовского свода залежь нефти и газоконденсата в отложениях коры выветривания и кровле ДЮК обнаружена на Северо-Варьеганском месторождении. В 2000 году получены промышленные притоки легкой нефти и газоконденсата из грубозернистого базального слоя юры в непосредственной близости от изучаемой территории в районе северовосточного погружения Ван-Еганской брахиантиклинали (скв. №№ 162-П, 162-Пбис и 163).

В 2002 году на территории деятельности ООО «ЛУКОЙЛ-Западная Сибирь» впервые получен приток нефти из скважины $150 П$ Западно-Котухтинского месторождения, пробуренной в пределах Северо-Сетейского поднятия. В ее разрезе нижнеюрские отложения залегают на базальтоидах, представленных пузыристой лавой андезит-дацитового состава (рисунок 2). При испытании КИИ-146 (совместно с пластом ЮВ ${ }_{11}$ ) в открытом стволе интервала 3601-3635 м получен приток нефти дебитом 4,87 м³/сут. После опробования интервала 3613-3622 м получен незначительный приток нефти дебитом по данным КВУ $2,0 \mathrm{~m}^{3} /$ сут, который после солянокислотной обработки составил $0,9 \mathrm{~m}^{3} /$ сут по ДУ. Существенного изменения дебита не последовало после дострела интервала 3604-3613 м, получен также незначительный приток нефти дебитом 0,5 м 3 суст при динамическом уровне 1767 м. В связи с непромышленностью полученных притоков и отсутствием методики выделения коллекторов в отложениях ДЮК залежь не выделялась. По результатам сейсморазведочных работ МОГТ-3D СП 15/00 ОАО «Башнефтегеофизика» по отражающему горизонту ОГ «А» выявлена ловушка с ресурсами по категории Д лл$-4833 / 967$ тыс. тонн.

По результатам поисково-разведочных работ на Северо-Варьеганском, Ван-Еганском и Западно-Котухтинском месторождениях стало очевидно, что залежи нефти в нижних горизонтах разреза не могут быть «разовым» явлением местного масштаба. К тому же результатами бурения сверхглубокой скважины СГ-6 (7502 м) опровергнуты представления о непрерывном уплотнении терригенных пород и отсутствии коллекторов на больших глубинах, установлена значительная роль процессов разуплотнения, коллекторы разного типа ниже 5 км зафиксированы как в осадочных отложениях, так и в магматических толщах триаса, в условиях высоких пластовых температур (больше $150{ }^{\circ} \mathrm{C}$ ) и АВПД получены притоки газа с глубины более 5-6 км (Белоконь-Карасева Т.В., Башкова С.Е., Беляева Г.Л. и др.). 


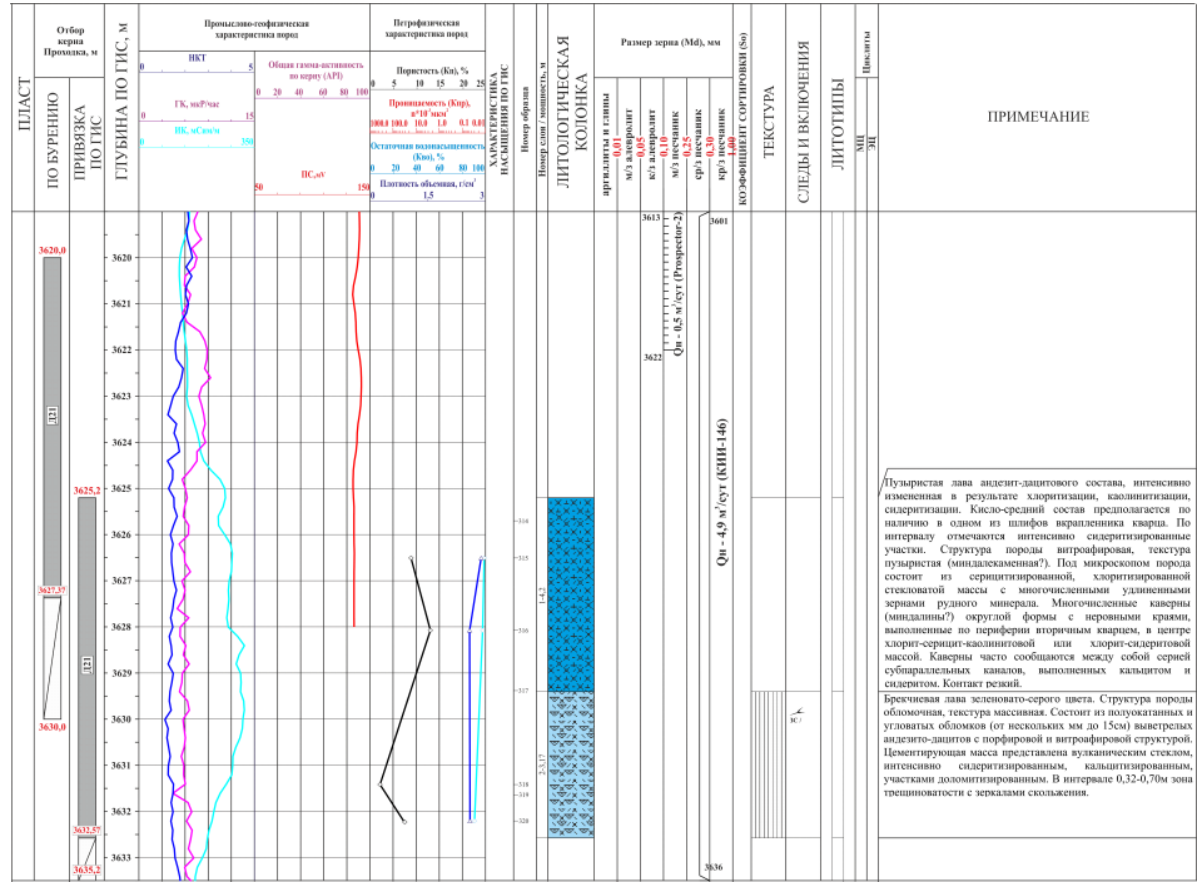

Рисунок 2 Литолого-физическая характеристика ДЮК в разрезе скважины 150П ЗападноКотухтинского месторождения

\section{Выводы}

Уточнена и детализирована региональная структурная схема по кровле доюрского комплекса с картированием сети тектонических нарушений, на основе комплексного анализа результатов детальных сейсморазведочных работ и данных бурения в породах ДЮК. На основании структурно-тектонического, палеотектонического анализа исследуемой территории установлено блоковое строение ДЮК, выявлены связанные с ним структуры растяжения земной коры, являющиеся геоструктурным признаком проницаемости отложений (А.И. Тимурзиев). Предложена схема вещественного состава отложений ДЮК, отражающих глубокие постгенетические изменения, связанные с дегазацией, высокой температурой, миграцией флюидов и сжатием УВ в зонах вторичной пористости и структурных разрушений пород фундамента. Выполнено вероятностное районирование перспектив нефтегазоносности по данным гравиразведки, магниторазведки, региональным структурным картам и данным бурения. На основе комплексирования геолого-геофизических материалов определены эталонные участки, перспективные на наличие УВ и предложена программа поискового бурения. Предлагаемый комплексный подход к изучению ДЮК, как нам представляется, позволит повысить эффективность поисков залежей нефти и газа в доюрском комплексе.

\section{Библиография}

1. Беккина С.М. Особенности геологического строения и перспективы нефтеносности доюрского фундамента центральной части Фроловской мегавпадины / С.М. Беккина, И.Ш. Усманов // Сб. науч. тр. - Сургут. науч.-исслед. и проект. ин-т, 2009. - С. 114-121.

2. Белоконь-Карасева Т.В. Перспективы нефтегазоносности глубокопогруженных отложений севера Западной Сибири по данным сверхглубокого бурения / Т.В. Белоконь-Карасева, С.Е. Башкова, Г.Л. Беляева [и др.] // Геология нефти и газа. - 2006. - № 6. - С. 2-10.

3. Тимурзиев А.И. Фундаментная нефть Западной Сибири: реальность и альтернативы / Горные ведомости. - 2016. - № 5-6. - С. 100-118. 


\section{References}

1. Bekkina S.M. Features of geological structure and Prospects of oil content of the Pre-Jurassic basement of the central part of the Frolovskaya megabasin. / Bekkina S.M, I.Sh. Usmanov // Collection of scientific papers - Surgut Research and Design Institute, 2009-p. 114-121.

2. Belokon-Karaseva T.V. Prospects of oil and gas content of deep-seated sediments of the north of Western Siberia according to superdeep drilling / T.V. Belokon-Karaseva, S.E. Bashkova, G.L. Belyaeva [and others]// The geology of oil and gas. -2006. -№6. -p. 2-10.

3. Timurziev A.I. Fundamental oil of Western Siberia: Reality and alternatives / Mountain sheets. -2016. -№5-6. -C.100-118. 